Journal of Science $\quad$ Gazi University

\title{
Flow and Heat Transfer in a Trapezoidal Cross-Sectional Microchannel Heat Sink Using Nanofluid
}

\author{
Faraz EGE $^{(1)}$, Oguz TURGUT ${ }^{(1)}$, Emre A. ELIBOL* \\ Gazi University, Faculty of Engineering, 06570, Ankara, Turkey
}

Highlights

- Thermal performance of nanofluids.

- $\mathrm{CuO}$-water and $\mathrm{Al}_{2} \mathrm{O}_{3}$-water nanofluids.

- Trapezoidal microchannel heat sink.

\section{Article Info}

Received: 06 Oct 2020

Accepted: 20 Jan 2021

\section{Keywords}

Nanofluid

Heat transfer

Microchannel

Heat sink

Numerical simulation

\begin{abstract}
In this study, the effects of microchannel number, volume concentration, Reynolds number, and nanofluid type on heat transfer and flow characteristics in the heat sink consisting of trapezoidal microchannels are investigated numerically. Governing equations are solved by assuming threedimensional, incompressible, steady and laminar flow. The channel material is chosen as copper, and a constant heat flux boundary condition is defined on the upper wall of heat sink. For two different nanofluids, $\mathrm{CuO}$-water and $\mathrm{Al}_{2} \mathrm{O}_{3}$-water, investigated parameters are the number of trapezoidal channels $(n=3-5)$ in the heat sink, Reynolds number $(\operatorname{Re}=200-1500)$, and volume concentration $(\varphi=0-4 \%)$. Results show that using nanoparticles in base fluid causes to increase both heat transfer coefficient and pressure drop. Heat transfer coefficient increases with increasing number of trapezoidal cross-sectional channel in the heat sink, nanofluid volume concentration and Reynolds number. Pressure drop enhances with enhancing Reynolds number and microchannel number in the heat sink. The nanofluid type and volume concentration do not importantly affect the friction factor. According to the performance index, it is seen that adding $\mathrm{CuO}$ nanoparticles in water is convenient, but $\mathrm{Al}_{2} \mathrm{O}_{3}$ nanoparticles in water is not appropriate. It is observed that volume concentration for $\mathrm{CuO}$-water nanofluid affects the thermal performance, but volume concentration for $\mathrm{Al}_{2} \mathrm{O}_{3}$-water nanofluid does not affect.
\end{abstract}

\section{INTRODUCTION}

The tremendous progression in the technology compels various devices to be miniaturized with a large number of parts. Microchannel heat sinks (MCHSs) have high heat transfer rates while heat transfer surface area is too large compared to the available volume. Due to this advantage, they are frequently used in some heat exchangers and electronic systems where high heat transfer rates are required. Although there are studies investigating the heat transfer and the flow characteristics of nanofluids within circular or semicircular cross sectional MCHSs [1,2], non-circular cross sectional MCHSs such as rectangular, triangular and trapezoidal have been used due to their more compactness in recent years. Some researchers stated that trapezoidal cross-sectional microchannels (MCs) have better heat transfer performance than rectangular, semicircle and square cross-sectional MCs because of larger heat transfer area [3-5]. MCHSs consisting of trapezoidal channels are used in electronic cooling, cooling of gas turbine blades, space systems, automobiles, bio-engineering, power plants and air conditioning systems [6,7]. In applications requiring high cooling performance, the using of nano-fluids such as $\mathrm{Al}_{2} \mathrm{O}_{3}$-water, $\mathrm{CuO}$-water, $\mathrm{TiO}_{2}$-water instead of employing conventional refrigerants such as ethylene glycol, water, and oil has become widespread. Geometry, number of channels, fluid type, nanoparticle concentration $\varphi$, nanofluid flow rate, and MC dimension affect the performance of MCHS [8-12]. In the literature, it is seen that there are several studies investigating heat transfer in laminar flow in heat exchangers consisting of trapezoidal MCs using various 
nanofluids. Chein and Chuang [11] examined experimentally the effects of flow rate and $\varphi$ using CuOwater nanofluid flowing in a MCHS consisting of trapezoidal MCs made of silicon, and it was stated that heat transfer rate increased as compared to water. Fani et al. [12] conducted a numerical study to see the effects of Brownian motion of nanoparticles, viscous dissipation, and some geometric parameters on heat transfer and flow characteristics for laminar flow. $\mathrm{CuO}$-water nanofluid was modeled as two-phase in MCHS with trapezoidal cross-section. Their results present that the effect of Brownian motion is inverse to the nanoparticle diameter and directly related to the both concentration value and temperature. $\mathrm{Li}$ and Kleinstreuer [13] conducted a numerical study to examine the thermal performance of $\mathrm{CuO}$-water nanofluid in trapezoidal cross-section MCHS for the volume concentration of $\varphi=0,1$ and $4 \%$ under laminar flow conditions. Two effective thermal conductivity model was used, and it was stated that there is a significant increase in cooling performance when nanofluid is used compared to only water. $\mathrm{Wu}$ et al. [14] experimentally analyzed the cooling performance of $\mathrm{Al}_{2} \mathrm{O}_{3}$-water nanofluid for $0,0.15$ and $0.26 \%$ volume concentration values in MCHSs consisting of trapezoidal channels made of silicon. Nanofluid was modeled as single-phase, and it was seen that Nusselt number $(\mathrm{Nu})$ enhanced with enhancing concentration value, Prandtl number and Reynolds number $(\mathrm{Re})$. Li and Kleinstreuer [15] conducted a numerical study to investigate the effects of $\mathrm{CuO}$-water nanofluid on entropy generation under laminar flow conditions in MCHS consisting of trapezoidal cross-section channels, and it was found that the use of nanofluid considerably reduced entropy generation. Mohammed et al. [16] carried out a numerical study to explore the effects of nanofluids consisting of different base fluids such as glycerine, ethylene glycol, and oil on cooling performance for laminar flow and three-dimensional assumptions for $2 \%$ volume concentration value in copper, titanium, steel and aluminum MCHS with 25 trapezoid section channels, and consequently, they observed that the type of frame material and base fluid significantly affected the cooling performance. The effect of volume concentration, hydraulic diameter, particle diameter and base fluid such as ethylene glycol and water on fluid hydrodynamics in trapezoidal MCs was experimentally and numerically explored by Singh et al. [17]. Authors observed that particle concentration, particle size and viscosity affect friction characteristics and easily visible in turbulent flow. Fani et al. [18] investigated numerically the nanoparticle size effect on cooling performance of $\mathrm{CuO}$-water nanofluid in MCHS consisting of trapezoidal section channels for laminar flow at 1-4\% volume concentration range using Eulerian-Eulerian method, and their results indicated that when the nanoparticle diameter enhances, the heat transfer rate and pressure loss increase. Yang et al. [19] investigated numerically in order to see the effects of $\mathrm{CuO}$-water nanofluid on heat transfer improvement within MCHS with trapezoidal cross section for very low concentration values and stated that the use of nanofluid decreased the thermal resistance compared to water. Yang and coauthors [20] numerically explored the effects of $\mathrm{CuO}$-water nanofluid on entropy generation under laminar flow condition in trapezoidal cross-section MCHS and found that entropy generation decreased compared to the situation in which water was used. The heat transfer within a trapezoidal cross-section silicon MCHS was numerically examined using two different methods for $\mathrm{CuO}$-water nanofluid and using innovative dispersion model for both $\mathrm{CuO}$-water and $\mathrm{Al}_{2} \mathrm{O}_{3}$-water nanofluids by Sheikhalipour and Abbassi [7, 21]. The results indicated that using nanofluid at low Reynolds numbers has no noticeable effect on heat transfer. Numerical and experimental investigations were conducted by Vinoth and Kumar [4, 5, 22] to explore the $\mathrm{Al}_{2} \mathrm{O}_{3}$-water nanofluid effect on the characteristics of flow and heat transfer for $0.25 \%$ concentration value in oblique finned MCHS consisting of channels with different geometrical sections. It was found that trapezoidal shaped hexagonal channel has better flow and heat transfer characteristics. This result has been the inspiration for the present study. Bakhshi et al. [23] reported numerically the effects of aspect ratio on flow and heat transfer characteristics in MCHS with trapezoidal cross-section using $\mathrm{Al}_{2} \mathrm{O}_{3}$-water nanofluid in laminar flow condition for $2 \%$ concentration value. They showed that changing the internal and external dimensions affects the flow and temperature fields. Khodabandeh and Abbassi [24] carried out a numerical study to understand the cooling performance of trapezoidal silicon MCHS, considering $\mathrm{Al}_{2} \mathrm{O}_{3}$-water nanofluid as two-phase. Study was performed for volume concentration of $1 \%$. Side angle of the channel was changed from $30^{\circ}$ to $78^{\circ}$. It was expressed that total thermal conductivity decreases when the side angle of MC decreases. The effects of material selection and hydraulic diameter on heat transfer under laminar flow within a trapezoidal MCHS were explored by Tran et al. [25] for $\mathrm{Al}_{2} \mathrm{O}_{3}$-water nanofluid and $\mathrm{TiO}_{2}-$ water nanofluid having volume concentrations less than $1 \%$. Authors reported that MCHS using copper as a substrate material has better performance compared to aluminium, silicon, iron, stainless steel. The giving best performance of copper has also been the inspiration for the present study. Three-dimensional heat transfer characteristics of laminar flow of $\mathrm{Al}_{2} \mathrm{O}_{3}$-water nanofluid within trapezoidal and circular shaped 
MCs with sinusoidal and stepped walls was explored by Jaferian et al. [26] using two phase model for the Reynolds number changing from 50 to 600 in two nanoparticle volume concentrations 2 and 4\%. It was concluded that the changing of cross-section from circular to trapezoid reduces the pressure drop but has not significantly affect the heat transfer. Literature review has showed that, in general, silicon is used as substrate material in MCHS. However, as stated in Tran et al. [25], copper as a substrate material enhances the cooling performance. Therefore, considering the situation mentioned above, MCHS material was chosen as copper in the present study. Also, when the literature is examined, it is seen that there are very few studies examining the effects of the number of channels forming MCHS on heat transfer and flow characteristics. In these studies, constant surface heat flux thermal boundary condition was defined for bottom plate, and insulated thermal boundary condition was applied to the top wall of the MCHS.

In this present study, the effects of MC number, concentration value and Reynolds number on heat transfer are investigated numerically under laminar and three-dimensional flow assumptions when $\mathrm{CuO}$-water nanofluid and $\mathrm{Al}_{2} \mathrm{O}_{3}$-water nanofluid are used in copper MCHS consisting of trapezoidal channels. Constant surface heat flux thermal boundary condition is defined to the upper wall of the MCHS. Present numerical study is conducted for both $\mathrm{CuO}$-water nanofluid and $\mathrm{Al}_{2} \mathrm{O}_{3}$-water nanofluid. The number of channel forming MCHS is in the range of $n=3-5$, Reynolds number is changed between $R e=200-1500$, and the concentration value of nanoparticles are varied in the range of $\varphi=0-4 \%$. Application of constant surface heat flux to the top plate of the MCHS and using copper material as a solid are the novelties of this study. This study, to the best of the authors' expertise, will be the first that investigates the effect of MC number in heat sink, concentration value of nanoparticles, Reynolds number and nanofluid type on heat transfer and flow characteristics for the flux applied to the top surface and copper material used as solid.

\section{FORMULATION OF THE PROBLEM}

\subsection{Model Description}

In this present study, simulations were performed for three different MCHSs consisting of three, four and five trapezoidal MCs. Due to computational domain region selected, microchannel number is chosen as 3, 4 and 5. Typical isometric view of MCHS consisting of five trapezoidal channels is shown in Figure 1. As seen in Figure 1, three-dimensional computational domain includes both trapezoidal-shaped flow field and copper made solid part. Constant heat flux $\dot{\mathrm{q}}_{\mathrm{w}}\left(=1 \times 10^{4} \mathrm{~W} / \mathrm{m}^{2}\right)$ is defined to the top surface of the heat sink. This value is chosen for the heat flux due to both improved lifetime of the electronic components and achieving cooling effect for the reliability $[4,5]$. Heat given to the copper material from top surface is disposed by flowing nanofluid through MCs. Fluid enters the MCHS at $\mathrm{z}=0$, flows in the z-direction, and leaves the MCHS at $\mathrm{z}=\mathrm{L}$. Geometric parameters of MCHS and its constituents are shown in Figure 1. In Figure 1, $a$ and $b$ are the bottom and top surface lengths of the MC, respectively. $L$ and $\mathrm{H}$ are the length and height of the heat sink, respectively. $\mathrm{W}$ is the width of the heat sink. $\mathrm{c}$ and $\mathrm{h}$ are the distance between two MCs and MC height, respectively.

The values of geometric parameters employed in this present numerical study are given in Table 1. Taking the value of total heat transfer surface area in MCHS as constant, the impacts of Re, MC number, nanofluid type, and concentration value on cooling performance are analyzed numerically.

$\varphi$ values for both $\mathrm{Al}_{2} \mathrm{O}_{3}$-water and $\mathrm{CuO}$-water nanofluids are chosen to be $0,0.1,0.5,1,2$ and $4 \%$. Here, $0 \%$ represents the pure water. The thermophysical properties of base fluid (water) and nanoparticles are shown in Table 2 at the temperature of 293.15K [16]. Investigated parameters are given in Table 3. 


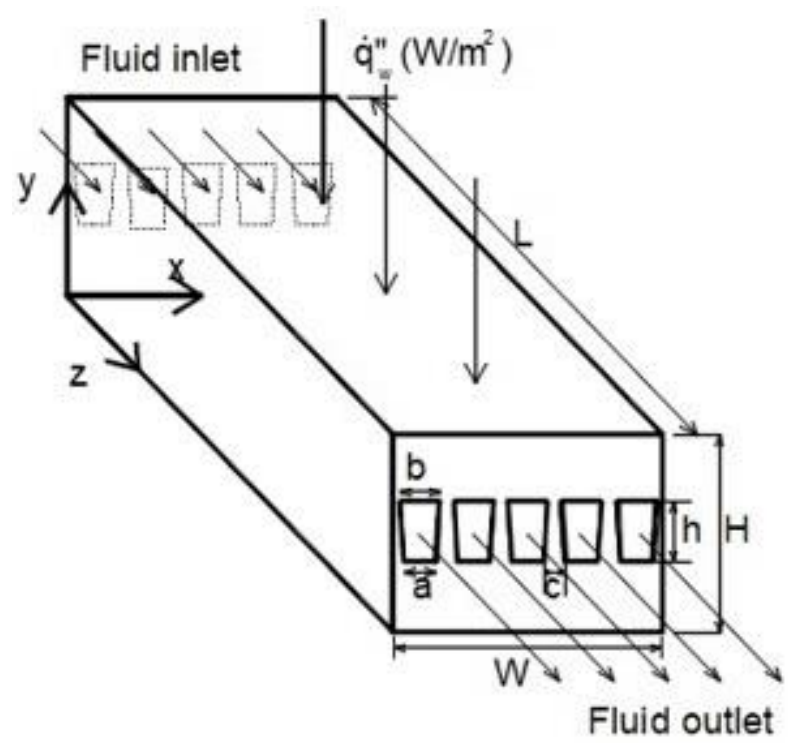

Figure 1. Isometric view of the MCHS

Table 1. Dimensions of the MCHS used in this study (dimensions in $\mu \mathrm{m}$ )

\begin{tabular}{lllllllll}
\hline MC number & $\mathrm{a}$ & $\mathrm{b}$ & $\mathrm{c}$ & $\mathrm{D}_{\mathrm{h}}$ & $\mathrm{h}$ & $\mathrm{H}$ & $\mathrm{L}$ & $\mathrm{W}$ \\
\hline 3 & 375 & 466 & 183.5 & 424 & 430 & 1500 & $1 \times 10^{4}$ & 1900 \\
4 & 290 & 350 & 204.5 & 366 & 430 & 1500 & $1 \times 10^{4}$ & 1900 \\
5 & 225 & 280 & 151.5 & 317 & 430 & 1500 & $1 \times 10^{4}$ & 1900 \\
\hline
\end{tabular}

Table 2. Base fluid and nanoparticle thermophysical properties at $293.15 \mathrm{~K}$

\begin{tabular}{llll}
\hline Properties & $\mathrm{Al}_{2} \mathrm{O}_{3}$ & Water & $\mathrm{CuO}$ \\
\hline$\rho\left(\mathrm{kg} / \mathrm{m}^{3}\right)$ & 3,970 & 998.2 & 6,500 \\
$\mu(\mathrm{kg} / \mathrm{m} \cdot \mathrm{s})$ & - & 0.001003 & - \\
$\mathrm{c}_{\mathrm{p}}(\mathrm{J} / \mathrm{kg} \cdot \mathrm{K})$ & 765 & $4,182.1$ & 535.6 \\
$\mathrm{k}(\mathrm{W} / \mathrm{m} \cdot \mathrm{K})$ & 40 & 0.598 & 20 \\
\hline
\end{tabular}

Table 3. Investigated parameters

\begin{tabular}{llll}
\hline Nanofluid & $\mathrm{Re}$ & $\varphi(\%)$ & $\mathrm{n}$ \\
\hline $\mathrm{Al}_{2} \mathrm{O}_{3}$-water & $200-1500$ & $0,0.1,0.5,1,2,4$ & $3,4,5$ \\
$\mathrm{CuO}$-water & $200-1500$ & $0,0.1,0.5,1,2,4$ & $3,4,5$ \\
\hline
\end{tabular}

\subsection{Governing Equations}

Assuming continuum approach, governing equations are given in Equations (1-3) for the assumptions of three-dimensional, laminar flow condition, conjugate heat transfer, incompressible, steady state, Newtonian fluid, constant properties and single phase with negligible dissipation, gravitational force and radiation energy transfer.

Continuity:

$$
\nabla \cdot \vec{V}_{\mathrm{f}}=0
$$

Momentum:

$$
\rho_{\mathrm{f}} \overrightarrow{\mathrm{V}}_{\mathrm{f}} \cdot \nabla \overrightarrow{\mathrm{V}}_{\mathrm{f}}=-\Delta \mathrm{P}_{\mathrm{f}}+\mu_{\mathrm{f}} \nabla^{2} \overrightarrow{\mathrm{V}}_{\mathrm{f}}
$$

Energy equation for fluid: 


$$
\overrightarrow{\mathrm{V}}_{\mathrm{f}} \nabla \mathrm{T}_{\mathrm{f}}=\alpha_{\mathrm{f}} \nabla^{2} \mathrm{~T}_{\mathrm{f}}
$$

Energy equation for solid:

$$
\mathrm{k}_{\mathrm{s}} \nabla^{2} \mathrm{~T}_{\mathrm{f}}=0
$$

where $\vec{V}, \rho, \mu$, and $\alpha$ present the fluid velocity vector, density, dynamic viscosity and thermal diffusivity, respectively. T, $\mathrm{P}$ and $\mathrm{k}$ indicate the temperature, pressure, and thermal conductivity, respectively. Subscripts s and $f$ denote the solid and fluid regions, respectively.

\subsection{Boundary Conditions}

Computational domain of the problem is solved using governing equations and employing appropriate boundary conditions. At the inlet of the computational domain, working fluid goes into the channel with constant and uniform temperature $\mathrm{T}_{\mathrm{i}}=293.15 \mathrm{~K}$ and velocity at $\mathrm{z}=0$ and exits at $\mathrm{z}=\mathrm{L}$. At the outlet of the channel, the flow is accepted to be atmospheric. That is, at the outlet of the channel, the change in flow direction of variables except pressure is neglected. No-slip boundary condition is accepted at all solid walls. Constant $1 \times 10^{4} \mathrm{~W} / \mathrm{m}^{2}$ heat flux is defined to the top wall of MCHS. All surfaces are considered insulated except the top surface of MCHS.

Therefore, boundary conditions at the inlet (i.e. at $\mathrm{z}=0$ ):

$$
\mathrm{u}=\mathrm{v}=0 ; \mathrm{w}=\mathrm{w}_{\mathrm{i}} ; \mathrm{T}_{\mathrm{f}}=\mathrm{T}_{\mathrm{i}}=293.15 \mathrm{~K}
$$

At the outlet (i.e. at $\mathrm{z}=\mathrm{L}$ ):

$$
\frac{\partial \mathrm{u}}{\partial \mathrm{z}}=\frac{\partial \mathrm{v}}{\partial \mathrm{z}}=\frac{\partial \mathrm{w}}{\partial \mathrm{z}}=\frac{\partial \mathrm{T}_{\mathrm{f}}}{\partial \mathrm{z}}=0 ; \mathrm{P}=\mathrm{P}_{\mathrm{atm}}
$$

At the fluid-solid interface:

$$
\mathrm{u}=\mathrm{v}=\mathrm{w}=0 ;-\mathrm{k}_{\mathrm{nf}} \frac{\partial \mathrm{T}_{\mathrm{f}}}{\partial \mathrm{z}}=-\mathrm{k}_{\mathrm{s}} \frac{\partial \mathrm{T}_{\mathrm{s}}}{\partial \mathrm{n}}
$$

At the top surface (i.e. at $\mathrm{y}=\mathrm{H}$ ):

$$
\mathrm{u}=\mathrm{v}=\mathrm{w}=0 ; \frac{\partial \mathrm{T}_{\mathrm{s}}}{\partial \mathrm{y}}=\frac{\dot{\mathrm{q}}_{\mathrm{w}}}{\mathrm{k}_{\mathrm{s}}}
$$

At the other surfaces of heat sink:

$$
\mathrm{u}=\mathrm{v}=\mathrm{w}=0 ; \frac{\partial \mathrm{T}_{\mathrm{s}}}{\partial \mathrm{n}}=0 .
$$

\subsection{Thermophysical Properties of Nanofluid}

Assuming single phase model with negligible Brownian diffusion, the following equations are used while the thermophysical properties of the nanofluids are calculated [4, 16, 22, 24]:

Density:

$$
\rho_{\mathrm{nf}}=\rho_{\mathrm{p}} \varphi+\rho_{\mathrm{bf}}(1-\varphi)
$$

Heat capacity: 


$$
\left(\rho c_{p}\right)_{n f}=\left(\rho c_{p}\right)_{p} \varphi+\left(\rho c_{p}\right)_{b f}(1-\varphi)
$$

Thermal conductivity:

$$
\frac{\mathrm{k}_{\mathrm{nf}}}{\mathrm{k}_{\mathrm{bf}}}=\frac{\mathrm{k}_{\mathrm{p}}+2 \mathrm{k}_{\mathrm{bf}}+2\left(\mathrm{k}_{\mathrm{p}}-\mathrm{k}_{\mathrm{bf}}\right) \varphi}{\mathrm{k}_{\mathrm{p}}+2 \mathrm{k}_{\mathrm{bf}}-2\left(\mathrm{k}_{\mathrm{p}}-\mathrm{k}_{\mathrm{bf}}\right) \varphi}
$$

Dynamic viscosity:

$$
\mu_{\mathrm{r}}=\frac{\mu_{\mathrm{nf}}}{\mu_{\mathrm{bf}}}=1+2.5 \varphi .
$$

As seen in Equations (5a-d), these properties depend only on particle volume concentration $\varphi$; in other words, nanoparticle size is not taken into account in the numerical studies.

Average Fanning friction factor (f) in trapezoidal MCHS is calculated as follows

$$
\mathrm{f}=\left(\frac{\Delta \mathrm{P}}{\mathrm{L}}\right) \frac{\mathrm{D}_{\mathrm{h}}}{2 \rho_{\mathrm{nf}} \mathrm{w}_{\mathrm{i}}^{2}} .
$$

For the energy balance of the flow within a channel at constant surface heat flux thermal boundary condition, fluid temperature at the exit section $\left(\mathrm{T}_{\mathrm{o}}\right)$ of the channel can be expressed as follows [27]

$$
\mathrm{T}_{\mathrm{o}}=\mathrm{T}_{\mathrm{i}}+\frac{\dot{\mathrm{q}}_{\mathrm{w}}^{\prime \prime} \mathrm{A}_{\mathrm{s}}}{\dot{\mathrm{m}}\left(\mathrm{c}_{\mathrm{p}}\right)_{\mathrm{nf}}} .
$$

Reynolds number $(\mathrm{Re})$ is expressed as

$$
\operatorname{Re}=\rho_{n f} W_{i} D_{h} / \mu_{n f} .
$$

Study is carried out for Re in the range of 200 and 1500 . Average Nusselt number $(\mathrm{Nu})$ which is the dimensionless heat transfer coefficient is calculated as

$$
\mathrm{Nu}=\mathrm{hD} \mathrm{h}_{\mathrm{h}} / \mathrm{k}_{\mathrm{nf}} .
$$

Heat transfer coefficient (h) is determined as

$$
\mathrm{h}=\dot{\mathrm{q}}_{\mathrm{w}}{ }_{\mathrm{w}} /\left(\mathrm{T}_{\mathrm{w}}-0.5\left(\mathrm{~T}_{\mathrm{i}}+\mathrm{T}_{\mathrm{o}}\right)\right) \text {. }
$$

\section{NUMERICAL METHOD}

ANSYS Fluent 17.0 software is employed in order to simulate the numerical analysis. Grid independence study is conducted to upgrade precision of the present numerical results. Typical mesh structure is seen in Figure 2. Fine meshes are used at fluid-solid interface due to conjugate heat transfer.

Mesh/grid indepence study is performed changing mesh number in the computational domain. For this purpose, different grid structures are selected to ensure the independence of solution at the highest value of $\mathrm{Re}=1500$. The values of $\mathrm{T}_{\mathrm{o}}, \mathrm{h}$ and $\mathrm{Nu}$ are calculated, and the calculated values for the grid independence study for heat sink with five MC are given in Table 4. It is observed that the changes in $\mathrm{Nu}, \mathrm{T}_{\mathrm{o}}$, and $\mathrm{h}$ values are not significant when the mesh number changes from 240,546 to 640,971. Therefore, mesh number of 240,546 is chosen as optimum mesh. When MC number is changed, mesh optimization study is repeated. 

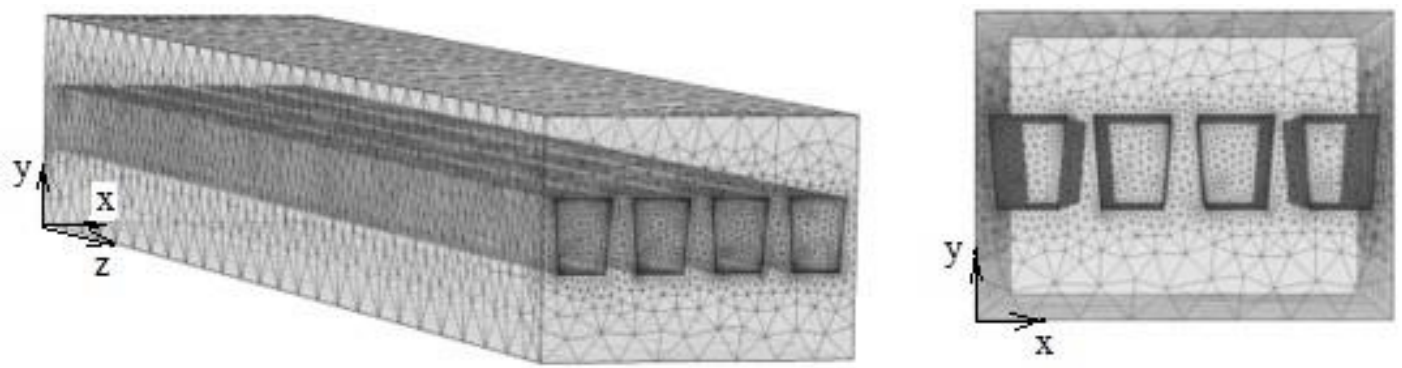

Figure 2. Typical mesh structure

Table 4. Effect of grid number on $T_{o}, h$ and $N u$

\begin{tabular}{llll}
\hline Grid & $T_{o}\left({ }^{\circ} \mathrm{C}\right)$ & $h\left(\mathrm{~W} / \mathrm{m}^{2} \cdot \mathrm{K}\right)$ & $\mathrm{Nu}$ \\
\hline 137,204 & 293.18 & $57,366.76$ & 26.17 \\
$\mathbf{2 4 0 , 5 4 6}$ & $\mathbf{2 9 3 . 1 7}$ & $\mathbf{5 7 , 0 9 4 . 2 1}$ & $\mathbf{2 6 . 0 5}$ \\
640,971 & 293.17 & $56,814.35$ & 25.92 \\
\hline
\end{tabular}

Continuity, momentum, and energy equations are discretized employing second order upwind scheme. For the pressure-velocity coupling, SIMPLE algorithm is choosen. Solution is lasted for the residuals of pressure, velocity, and energy until $1 \times 10^{-6}$.

\section{RESULTS AND DISCUSSION}

\subsection{Code Validation}

The study of Koyuncuoglu et al. [28] which is the experimental study of laminar flow in a rectangular MCHS with $200 \mu \mathrm{m}$ wide, $50 \mu \mathrm{m}$ high and $1 \mathrm{~cm}$ long for pure water was conducted for validation. Heat flux is employed to the bottom plate of the MCHS. According to laminar theory [29], the relation between $\mathrm{Re}$ and $\mathrm{f}$ for the fully developed laminar flow within a rectangular cross-sectional channel whose aspect ratio is 4 is given as

$$
\mathrm{fRe}=18.23
$$
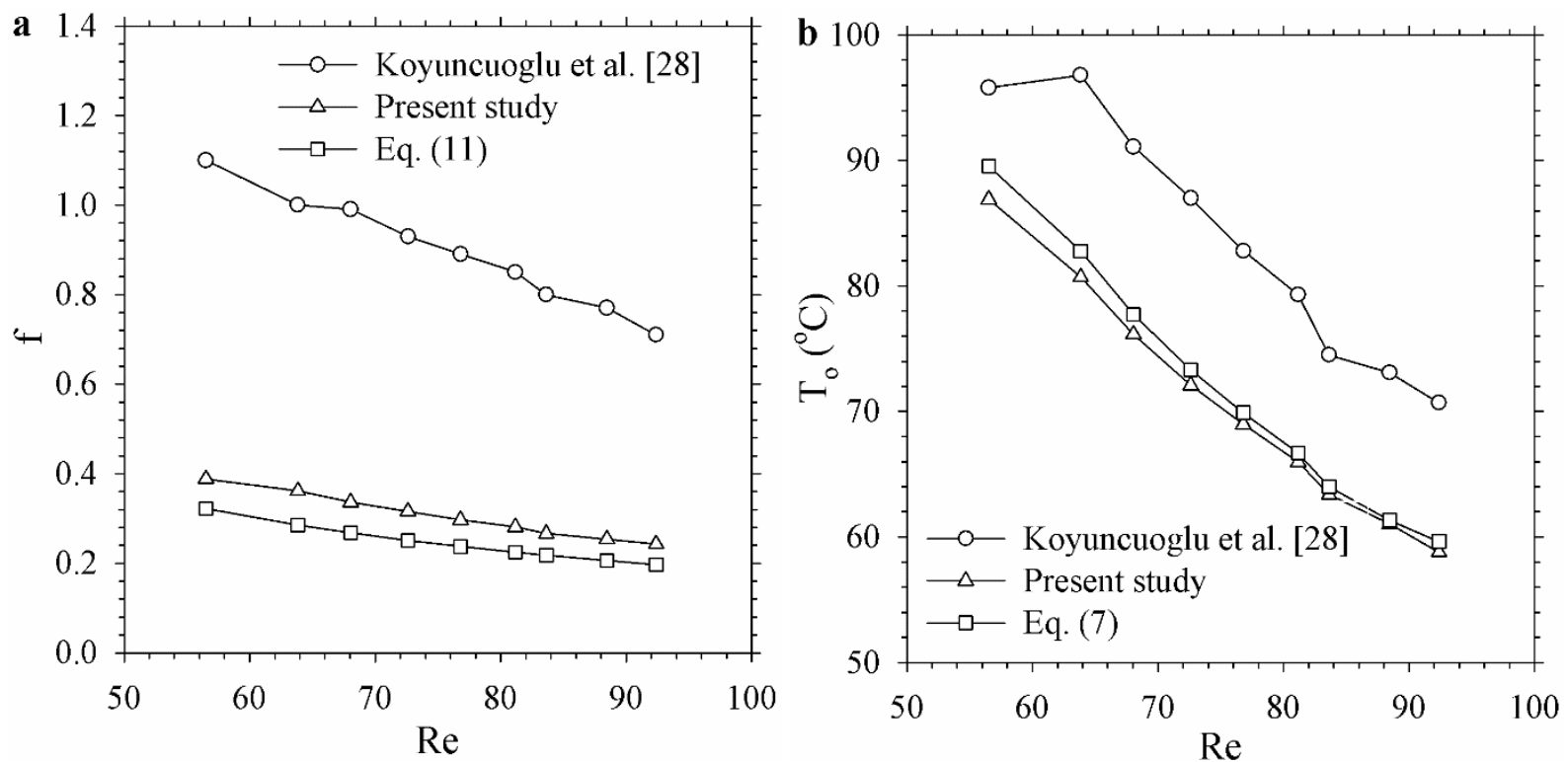

Figure 3. Comparison of the present numerical results with the literature study; $\boldsymbol{a} f, \boldsymbol{b} T_{o}$ 
For the comparison purpose, $f$ and $\mathrm{T}_{\mathrm{o}}$ obtained from the present study, Koyuncuoglu et al. [28], and laminar theory, i.e. Equations (7) and (11), are shown in Figure 3 as a function of Re. It may be detected that the present numerical study results keep pace with the results of the boundary layer theory, i.e. Equations (7), and (11). However, it is seen that the experimental results of Koyuncuoglu et al. [28] are higher than the results obtained from the present numerical study and both Equations (7) and (11). However, the results of numerical study are in good harmony with the results of laminar theory. That is, comparison of the results shows that the results of [28] show higher values than that of present numerical and laminar theory.

\subsection{The Results of the Present Numerical Study}

After validation studies, numerical analysis is conducted for heat transfer and laminar flow within trapezoidal MCHS using $\mathrm{CuO}$-water and $\mathrm{Al}_{2} \mathrm{O}_{3}$-water nanofluids. The effects of the trapezoidal $\mathrm{MC}$ number (n) inside heat sink, the type of nanofluid, Re, and $\varphi$ on both heat transfer and flow characteristics are numerically explored for the constant surface heat flux thermal boundary condition. Numerical study is carried out for heat sink with trapezoidal MCs for $n=3-5, \operatorname{Re}=200-1500$ and $\varphi=0-4 \%$.

\subsubsection{The effects of investigated parameters on velocity distribution}

In order to see the effect of Re, $\varphi$, nanofluid type, and $\mathrm{n}$ on velocity field, typical velocity profiles are displayed in Figure 4. Figure 4a demonstrates the effect of Re on velocity field at the exit (i.e. at $\mathrm{z}=10 \mathrm{~mm}$ ) of middle $\mathrm{MC}$ in the heat sink with $\mathrm{n}=5$ for $\varphi=1 \%$ and $\mathrm{CuO}$-water nanofluid. Results are given for $\mathrm{Re}=200$ and $\mathrm{Re}=1000$. It is observed that the higher Reynolds number is, the thinner velocity boundary layer thickness occurs. In addition, results show that maximum velocity is seen at the center of the MC, and velocity decreases as it is moved from the center towards the wall due to increasing wall stress near the wall. It is also viewed that velocity magnitude enhancess with enhancing Reynolds number, as expected. That is, Reynolds number affects the velocity distribution in the channel.

To view the effect of nanofluid type on velocity distribution, typical velocity contours at the outlet (i.e. at $\mathrm{z}=10 \mathrm{~mm}$ ) of middle $\mathrm{MC}$ in the heat sink with $\mathrm{n}=5$ for $\mathrm{Al}_{2} \mathrm{O}_{3}$-water and $\mathrm{CuO}$-water nanofluids are shown in Figure $4 \mathrm{~b}$ for $\varphi=1 \%$ and $\mathrm{Re}=200$. It can be said that nanofluid type does not significantly affect the velocity distribution.

Figure $4 \mathrm{c}$ indicates the velocity contours at $\mathrm{z}=5 \mathrm{~mm}$ section of middle $\mathrm{MC}$ in the heat sink with $\mathrm{n}=5$ and $\mathrm{Re}=500$ for $\mathrm{CuO} /$ water nanofluid for two different nanofluid volume concentrations, $\varphi=0.5 \%$ and $4 \%$. Results show that velocity contours for $\varphi=0.5 \%$ and $4 \%$ are similar to each other. It can be said that volume concentration of nanofluid does not importantly affect the velocity distribution.

To show the effect of $\mathrm{n}$ on velocity distribution, typical velocity contours at $\mathrm{z}=10 \mathrm{~mm}$ (outlet section), $\varphi=4 \%$ and $\mathrm{Re}=500$ are presented in Figure $4 \mathrm{~d}$ for $\mathrm{Al}_{2} \mathrm{O}_{3} /$ water nanofluid for the middle $\mathrm{MC}$ in the heat sink with $n=3$ and 5 . Results point out that MC number in heat sink does not significantly affect the velocity distribution.

\subsubsection{The effects of investigated parameters on temperature distribution}

Figures 5a-d show the effects of Re, nanofluid type, $\varphi$ and MC number on temperature field, respectively. To indicate the effect of Re on temperature distribution, typical temperature contours at two different Reynolds numbers $\mathrm{Re}=200$ and 1000 for $\mathrm{CuO}$ /water nanofluid and volume concentration $\varphi=4 \%$ are shown in Figure $5 \mathrm{a}$ at $\mathrm{z}=5 \mathrm{~mm}$ of middle $\mathrm{MC}$ in the heat sink with $\mathrm{n}=5$. It is seen in Figure $5 \mathrm{a}$ that Reynolds number affects the temperature field. It is also seen that temperature boundary layer thickness declines with enhancing Reynolds number. Therefore, decreasing in temperature boundary layer thickness results in increasing heat transfer. 

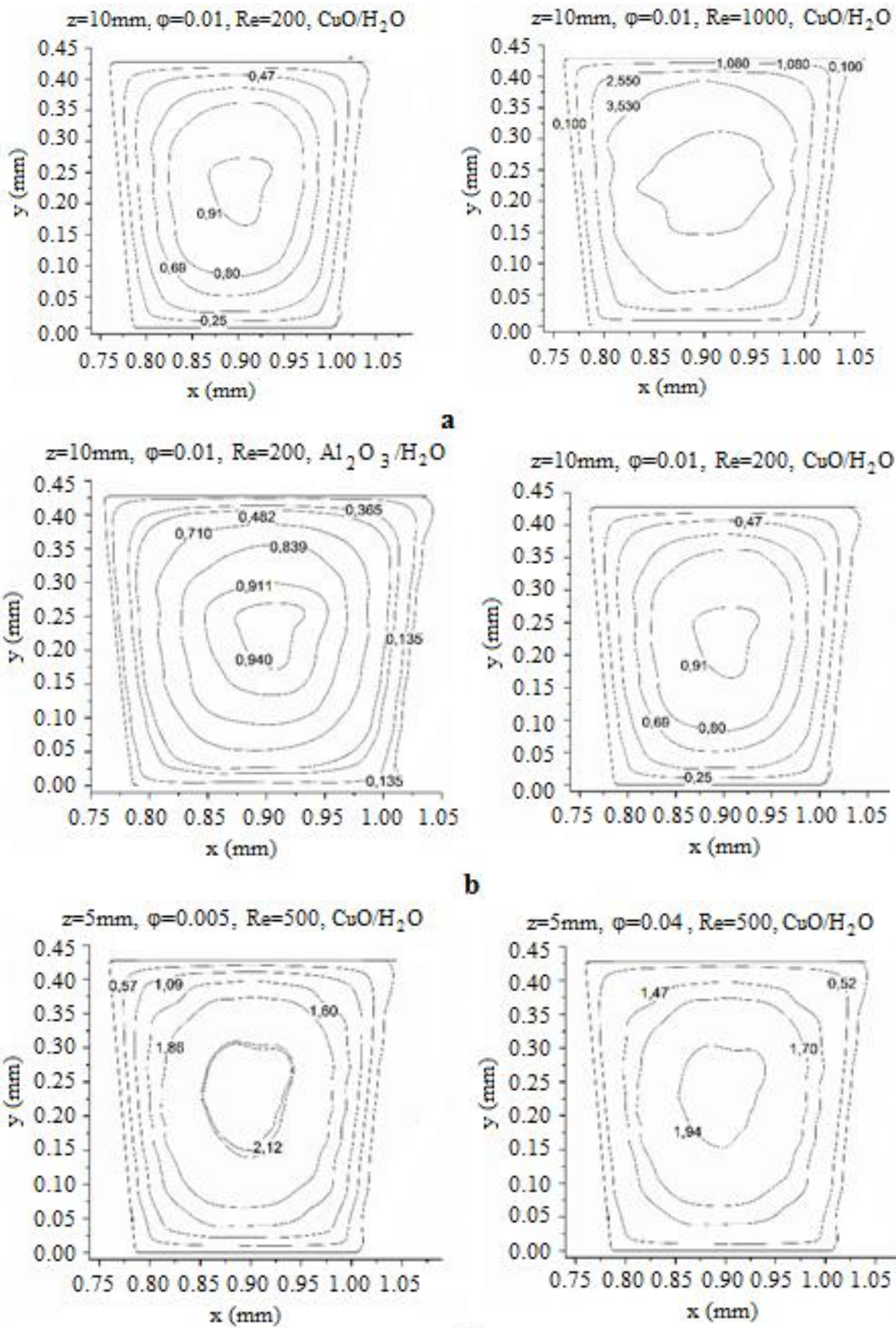

b

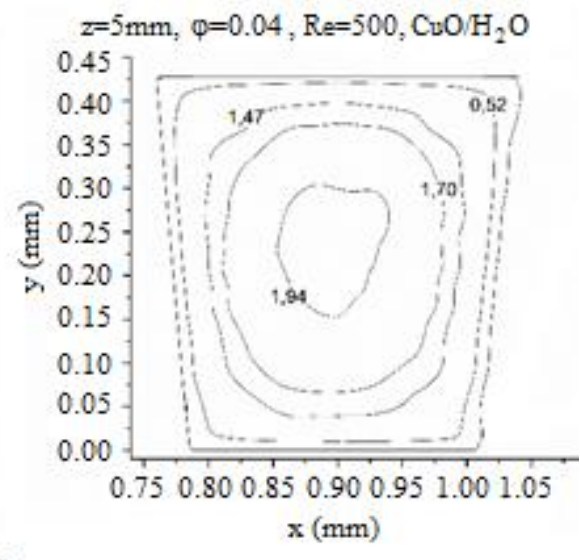

$\mathrm{n}=3, z=10 \mathrm{~mm}, \varphi=0.04, \mathrm{Re}=500, \mathrm{Al}_{2} \mathrm{O}_{3} / \mathrm{H}_{2} \mathrm{O}$

c
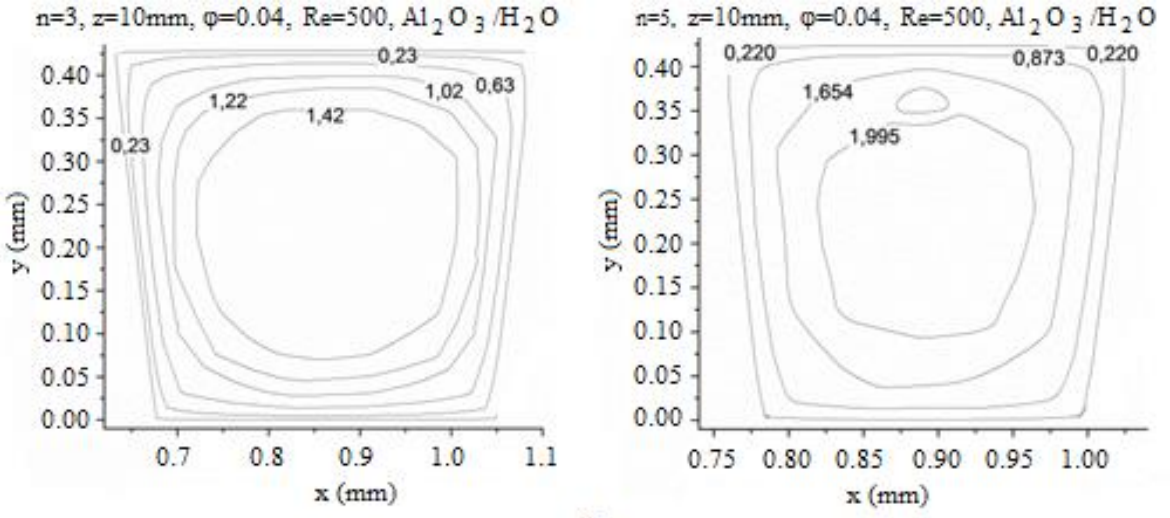

d

Figure 4. Effect of $\boldsymbol{a} R e, \boldsymbol{b}$ nanofluid type, $\boldsymbol{c} \varphi$, and $\boldsymbol{d} n$ on velocity distribution 
With regard to Figure 5b, typical temperature contours at the outlet section (i.e. at $\mathrm{z}=10 \mathrm{~mm}$ ) of middle $\mathrm{MC}$ in the heat sink with $\mathrm{n}=5$ for $\mathrm{Al}_{2} \mathrm{O}_{3}$-water nanofluid and $\mathrm{CuO}$-water nanofluid at $\mathrm{Re}=200$ and $\varphi=4 \%$ are given in order to view the effect of nanofluid type on temperature distribution. Results show that temperature distributions for two nanofluids are approximately the same. It can be said that nanofluid type does not significantly affect the temperature distribution.

In order to see whether the nanofluid volume concentration affects the temperature distribution, typical temperature contours are given in Figure $5 \mathrm{c}$ at $\mathrm{z}=5 \mathrm{~mm}$ of middle $\mathrm{MC}$ in the heat sink with $\mathrm{n}=5$ for $\mathrm{Re}=500$ and $\mathrm{CuO} /$ water nanofluid at $\varphi=0.5 \%$ and $4 \%$. Results show that similar profiles are seen in Figure $5 \mathrm{c}$ for two nanofluid volume concentrations.

Typical temperature contours at the outlet $(\mathrm{z}=10 \mathrm{~mm})$ of middle MC in the heat sink with $\mathrm{n}=3$ and 5 are shown in Figure $5 \mathrm{~d}$ at $\varphi=4 \%$ for $\mathrm{Al}_{2} \mathrm{O}_{3} /$ water nanofluid to present effect of $\mathrm{MC}$ number within the heat sink on temperature distribution. It is seen that similar temperature distribution is obtained.

\subsubsection{The effects of investigated parameters on outlet temperature}

To see the effects of both $\mathrm{Re}$ and $\varphi$ value on outlet temperature, typical outlet temperature for $\mathrm{Al}_{2} \mathrm{O}_{3}$-water nanofluid is shown in Figure 6 as a function of Re at different $\varphi$ values for the MC numbers of $n=3$ and 5 . A careful examination of results shows that outlet temperature increases slightly when nanoparticle concentration increases. This result can also be seen in temperature distribution (please see Figure 5c). That is, adding nanoparticle into base fluid carries more energy. In general, it can be said that $\varphi$ value of the $\mathrm{Al}_{2} \mathrm{O}_{3}$-water nanofluid does not significantly affects the outlet temperature of the nanofluid. This can be attributed to the amount of applied heat flux. In addition, this can be interpreted as the MC length is small, and it causes the fluid to escape from the MC without heating up sufficiently through the channel. As seen in Figure 6, outlet temperature of the fluid diminishes with increasing Re in virtue of increasing mass of fluid to carry out the same amount of heat. This result agrees with the results of Figure 5a. Comparison of Figures $6 a$ and $6 b$ show that outlet fluid temperature decreases slightly with increasing MC number. The results of temperature distribution (see Figure 5d) confirm this result.

To explore the effects of nanofluid type and MC number on fluid outlet temperature, fluid outlet temperatures at $\varphi=0.1 \%$ and $4 \%$ are plotted in Figure 7 as a function of $\mathrm{Re}$ for $\mathrm{CuO}$-water and $\mathrm{Al}_{2} \mathrm{O}_{3}$-water nanofluids at MC number $n=3-5$. The results of pure water are also shown in Figure 7. Results show that outlet temperature of the nanofluid reduces while the MC number within MCHS enhances at a given Re. It is understandable that the number of MC in MCHS does not significantly affect the outlet temperature at the low $\varphi$ values. According to Figure 7, it is seen that the outlet temperature in the case of using $\mathrm{CuO}-$ water nanofluid is slightly higher than that of using $\mathrm{Al}_{2} \mathrm{O}_{3}$-water nanofluid. Figure 7 indicates that outlet temperature of nanofluid diminishes with the increasing Re. In addition, it can be said that the nanofluid type and the number of MC in MCHS do not significantly affect the outlet temperature of nanofluid. Similar results can also be seen from temperature contours given in Figures 5b and 5d.

\subsubsection{The effects of investigated parameters on $h$ and $\mathrm{Nu}$}

Typical variation of heat transfer coefficient versus $\mathrm{Re}$ is given in Figure 8 for $\mathrm{Al}_{2} \mathrm{O}_{3}$-water nanofluid at various concentration values for the $\mathrm{MC}$ number $\mathrm{n}=3$ and 5 . Results show that $\mathrm{h}$ enhances with enhancing $\varphi$ at a given Re. It is conluded that when $n=3$, heat transfer coefficient at $\operatorname{Re}=200$ increases $0.15 \%$ when $\varphi=0.1 \%$ compared to pure water. In addition, $\mathrm{h}$ at $\mathrm{Re}=200$ enhances approximately $5.9 \%$ when $\varphi=4 \%$ compared to pure water. At $\mathrm{Re}=1500$ for $\mathrm{n}=3$, results exhibit that heat transfer coefficient raises by $0.11 \%$ and $4.37 \%$ compared to water when $\varphi=0.1 \%$ and $4 \%$, respectively. Results point out that $\mathrm{h}$ increases with increasing Re. When the Re changes from 200 to 1500 at $n=3$, $h$ of the MCHS increases by a factor 1.76 for the $\mathrm{Al}_{2} \mathrm{O}_{3}$-water nanofluid with $\varphi=4 \%$, but $\mathrm{h}$ enhances by a factor of 1.89 for $\mathrm{n}=5$. Results show that adding $\mathrm{Al}_{2} \mathrm{O}_{3}$ nanoparticle in water results in increasing heat transfer coefficient. 

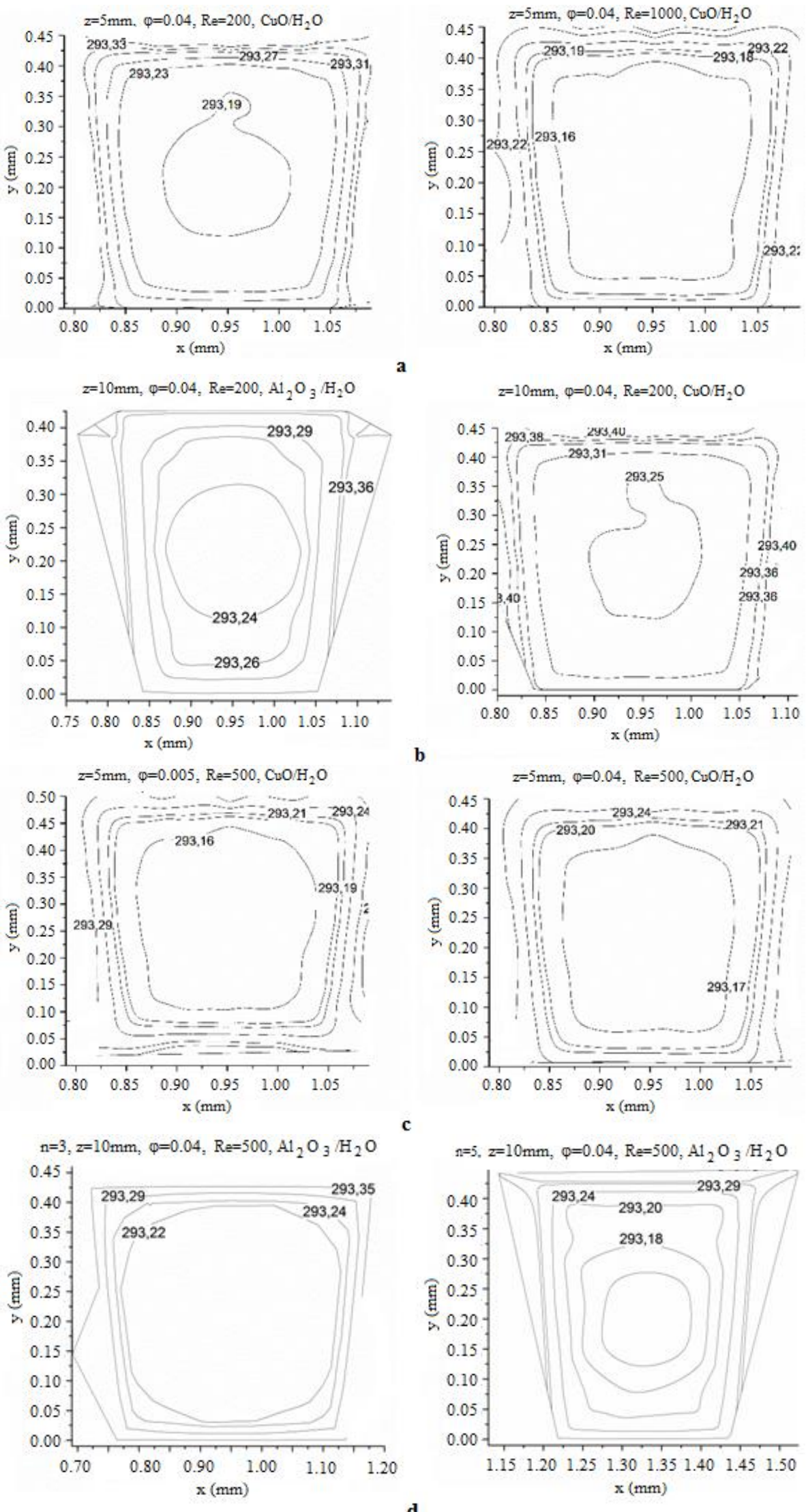

Figure 5. Effect of $\boldsymbol{a} R e, \boldsymbol{b}$ nanofluid type, $\boldsymbol{c} \varphi$, and $\boldsymbol{d} n$ on temperature distribution 

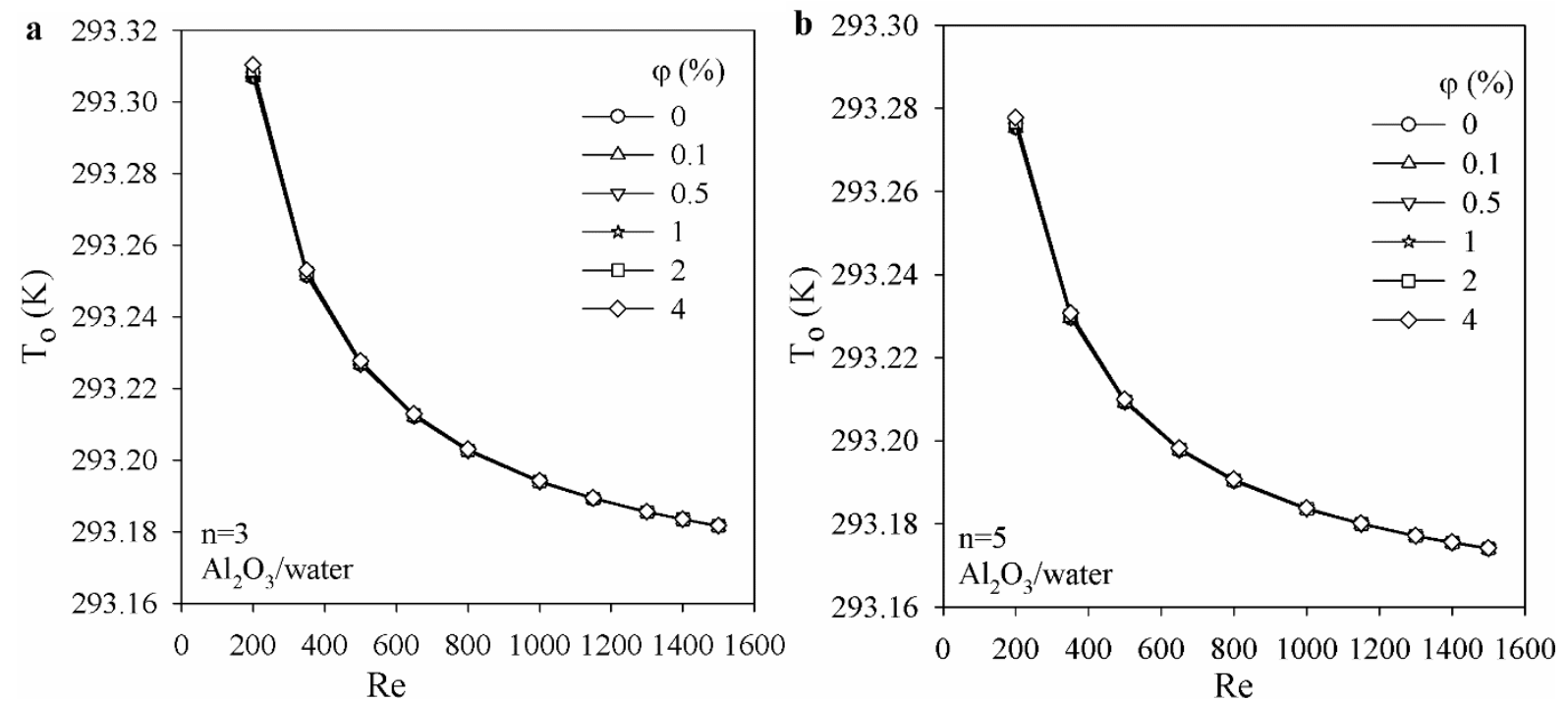

Figure 6. The variation of $T_{o}$ with Re at different $\varphi$ values for $\mathrm{Al}_{2} \mathrm{O}_{3}$-water nanofluid; $\boldsymbol{a} n=3, \boldsymbol{b} n=5$
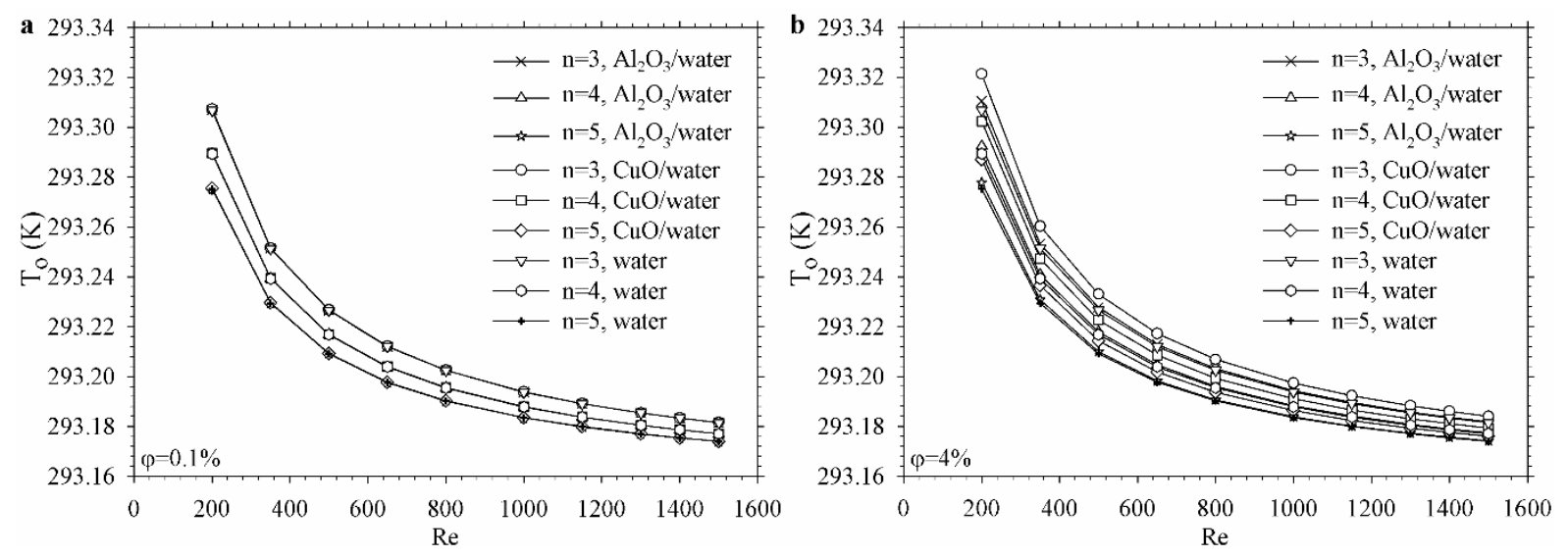

Figure 7. The effect of nanofluid type and $n$ on $T_{o} ; \boldsymbol{a} \varphi=0.1 \%, \boldsymbol{b} \varphi=4 \%$
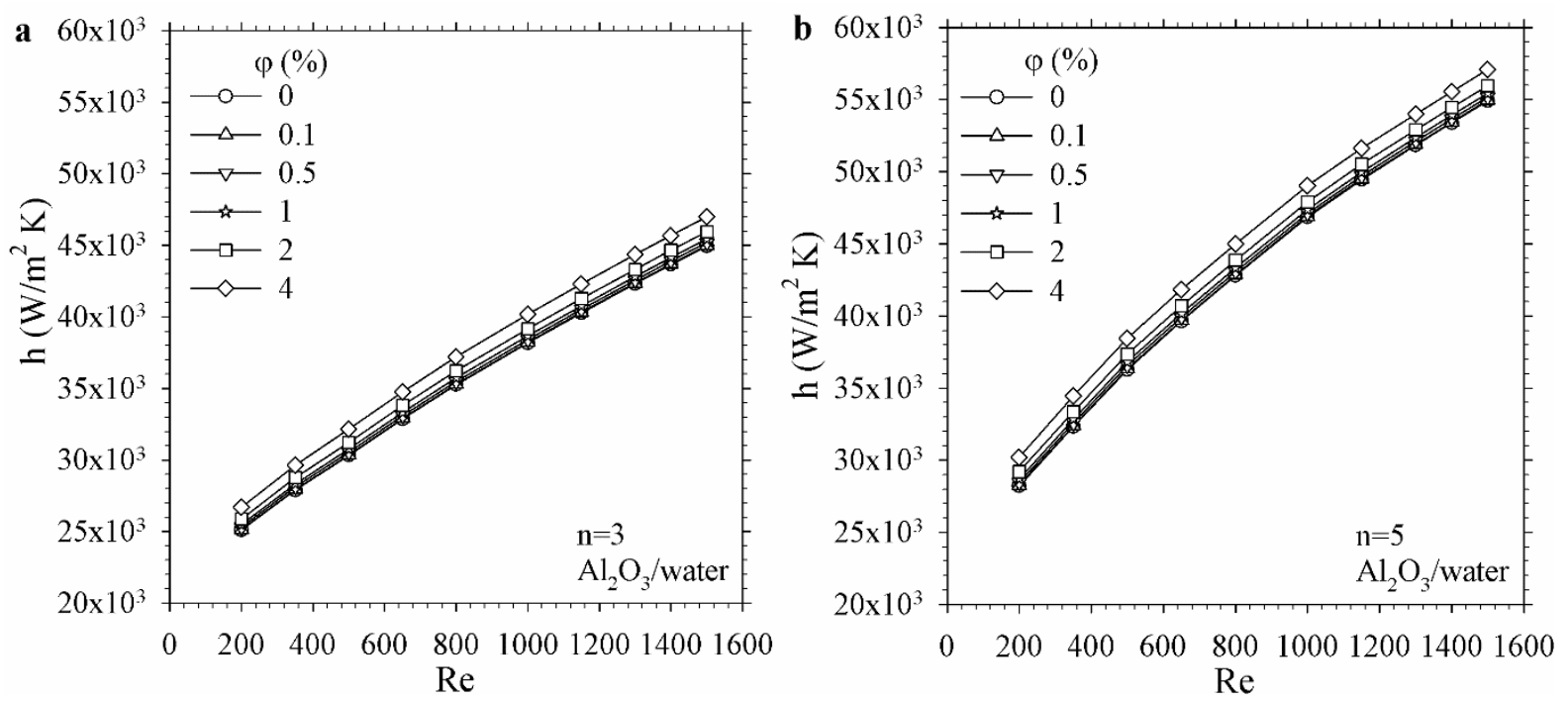

Figure 8. $h$ versus Re at different $\varphi$ values for $\mathrm{Al}_{2} \mathrm{O}_{3}$-water nanofluid; $\boldsymbol{a} n=3, \boldsymbol{b} n=5$ 
Figure 9 presents the $\mathrm{h}$ as a function of Re at three different $\mathrm{MC}$ numbers for $\mathrm{Al}_{2} \mathrm{O}_{3}$-water and $\mathrm{CuO} / \mathrm{water}$ nanofluids at two different volume concentration of nanofluids $\varphi=0.1$ and $4 \%$. Figure 9 points out that $h$ enhances when MC number in heat sink increases at a given Re. It is also seen that $h$ of the $\mathrm{Al}_{2} \mathrm{O}_{3}$ - $\mathrm{water}$ nanofluid is slightly higher than the $\mathrm{h}$ of the $\mathrm{CuO}$-water nanofluid.
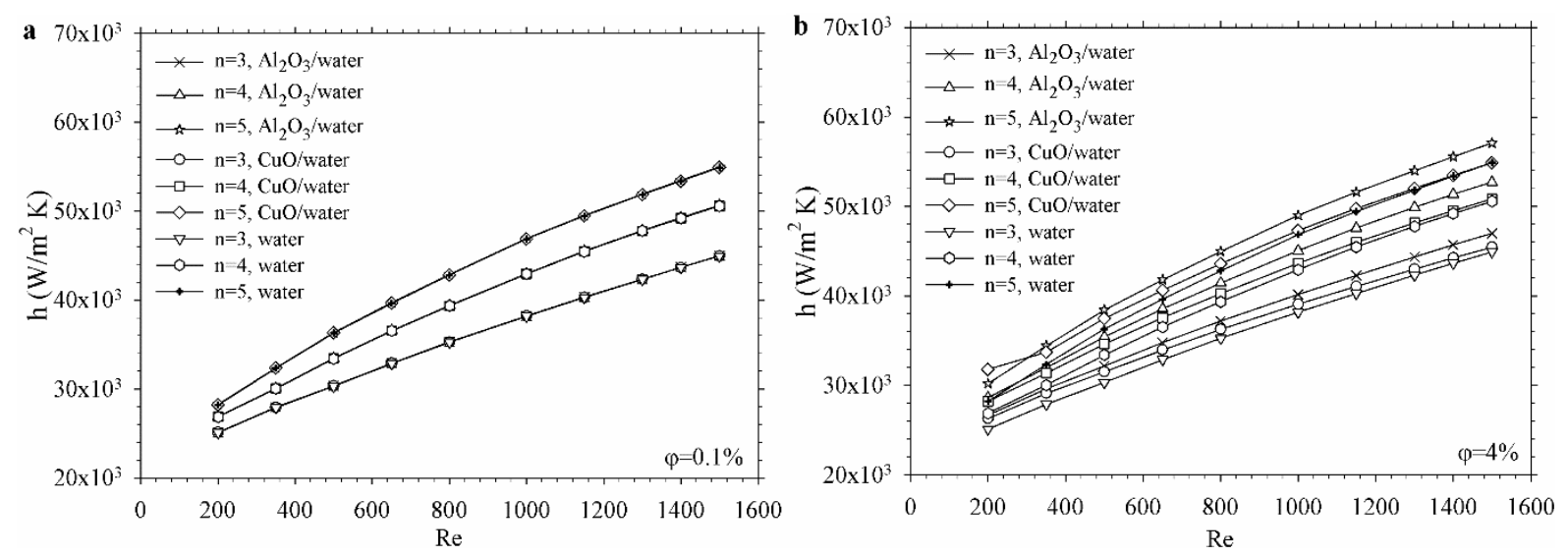

Figure 9. The effect of nanofluid type and $n$ on $h ; \boldsymbol{a} \varphi=0.1 \%, \boldsymbol{b} \varphi=4 \%$

Typical $\mathrm{Nu}$ values with $\mathrm{Re}$ for various $\varphi$ are shown in Figure 10 for the $\mathrm{Al}_{2} \mathrm{O}_{3}$-water nanofluid when the number of trapezoidal microchannels in the heat sink is three and five. As can be viewed in Figure 10, Nu enhances with enhancing Re. In addition, results show that the Nu decreases with enhancing $\varphi$ at a given Re. When the $\varphi$ increases, the thermal conductivity $(k)$ and $h$ increase. Since the amount of increment in $k$ is higher than the amount of increment in $\mathrm{h}$ when $\varphi$ enhances; therefore, Nusselt number decreases. Results show that $\mathrm{Nu}$ depends on $\mathrm{Re}$ and $\varphi$. In addition, $\mathrm{Nu}$ decreases when the $\mathrm{MC}$ number enhances.
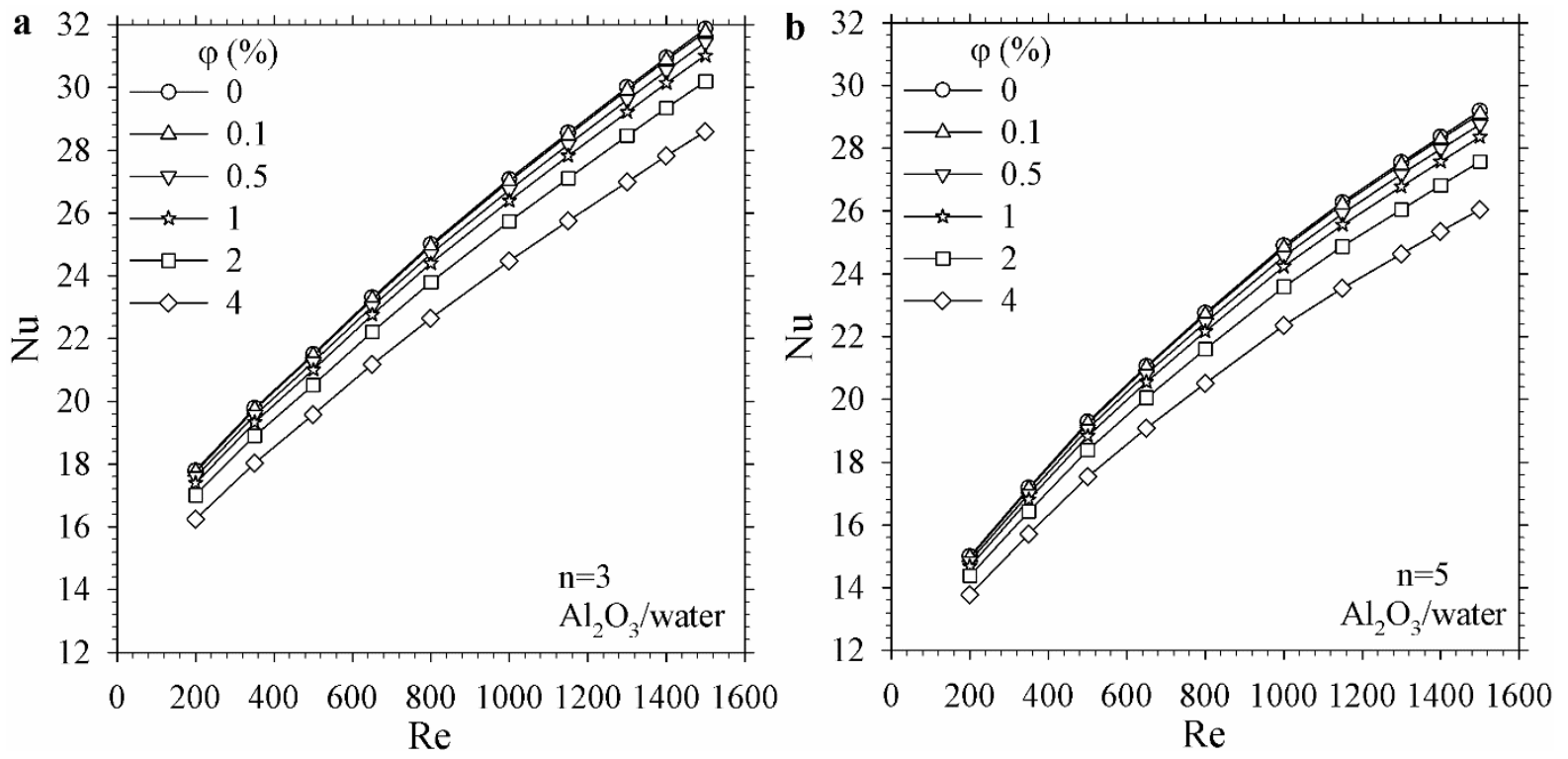

Figure 10. Effect of $\varphi$ on $\mathrm{Nu}$ for $\mathrm{Al}_{2} \mathrm{O}_{3}$-water nanofluid; $\boldsymbol{a} n=3 \boldsymbol{b} n=5$

When carefully examined the Figures 8 and 10, for instance at a given Reynolds number at $\varphi=4 \%$, heat transfer coefficient has the highest value and $\mathrm{Nu}$ has the lowest value. This can be explained as that, when nanoparticles are added into the base fluid, the amount of growth in $\mathrm{k}$ is higher than the amount of growth in h. Therefore, excessive growth in thermal conductivity causes a reduction in Nusselt number value.

To see the effect of nanofluid type and microchannel number in heat sink on Nusselt number, Nusselt number is plotted in Figure 11 versus $\mathrm{Re}$ for $\mathrm{Al}_{2} \mathrm{O}_{3}$-water nanofluid and $\mathrm{CuO}$-water nanofluid at $\mathrm{n}=3-5$ for 
$\varphi=0.1$ and 4\%. As can be viewed in Figure 11, Nu diminishes with enhancing MC number in the heat sink at a given Re. In addition, as $\varphi$ enhances, $\mathrm{Nu}$ for both nanofluids decreases at a given $\mathrm{MC}$ number. This can be explained as that $\mathrm{Nu}$ depends on $\mathrm{h}$ and $\mathrm{k}$. At a given Reynolds number, $\mathrm{h}$ and $\mathrm{k}$ of the $\mathrm{Al}_{2} \mathrm{O}_{3}$-water nanofluid is higher than $\mathrm{h}$ and $\mathrm{k}$ of the $\mathrm{CuO}$-water nanofluid.
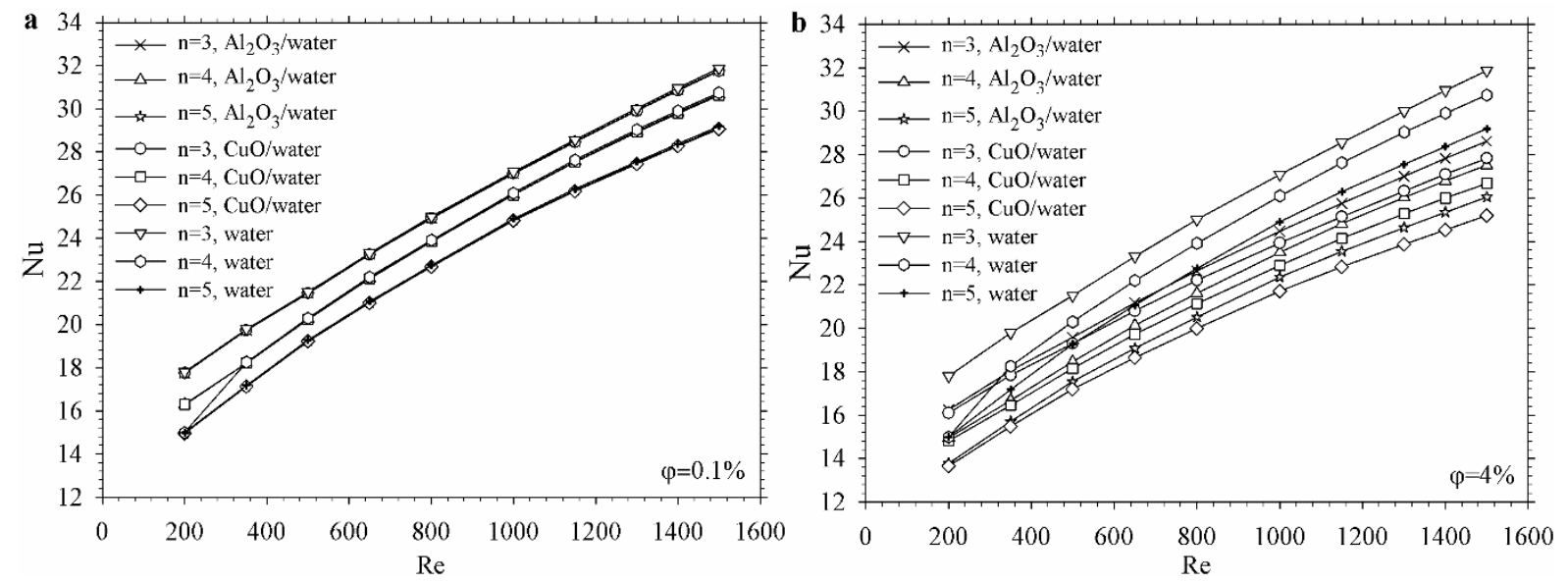

Figure 11. Effect of nanofluid type and $n$ on $N u ; \boldsymbol{a} \varphi=0.1 \%, \boldsymbol{b} \varphi=4 \%$

\subsubsection{The effects of investigated parameters on $\Delta P$ and $f$}

Figure 12 presents the pressure loss $(\Delta \mathrm{P})$ as a function of $\mathrm{Re}$ for $\mathrm{Al}_{2} \mathrm{O}_{3}$-water nanofluid and CuO-water nanofluid at $\varphi=0.1$ and $4 \%$. Figure 12 indicates that $\triangle \mathrm{P}$ in the MCHS enhances with enhancing MC number at a given Re. As $\varphi$ increases, $\Delta \mathrm{P}$ of the $\mathrm{Al}_{2} \mathrm{O}_{3}$-water nanofluid is greater than the $\Delta \mathrm{P}$ of the CuO-water nanofluid at the same $\mathrm{MC}$ number. $\Delta \mathrm{P}$ raises with raising $\mathrm{Re}$, which is consistent with the result of $\mathrm{Wu}$ et al. [14]. It is seen that $\Delta P$ for nanofluid is higher than that of pure water (i.e. $\varphi=0 \%$ ) owing to higher viscosity. Comparing Figures $12 \mathrm{a}$ and $12 \mathrm{~b}$, it is viewed that adding nanoparticles into water results in enhancing viscosity, and the enhancing of viscosity results in higher $\Delta \mathrm{P} . \Delta \mathrm{P}$ for $\mathrm{Al}_{2} \mathrm{O}_{3}$-water nanofluid with volume concentration of $4 \%$ at $\mathrm{Re}=1500$ and $n=3$ is $7.8 \%$ higher than that of pure water, i.e. $\varphi=0 \%$. Pressure loss of $\mathrm{Al}_{2} \mathrm{O}_{3}$-water is greater than the pressure loss of $\mathrm{CuO}$-water nanofluid at $\varphi=4 \%$. At low nanofluid volume concentrations, e.g. at $\varphi=0.1 \%$, nanofluid type does not significantly affect the pressure loss.
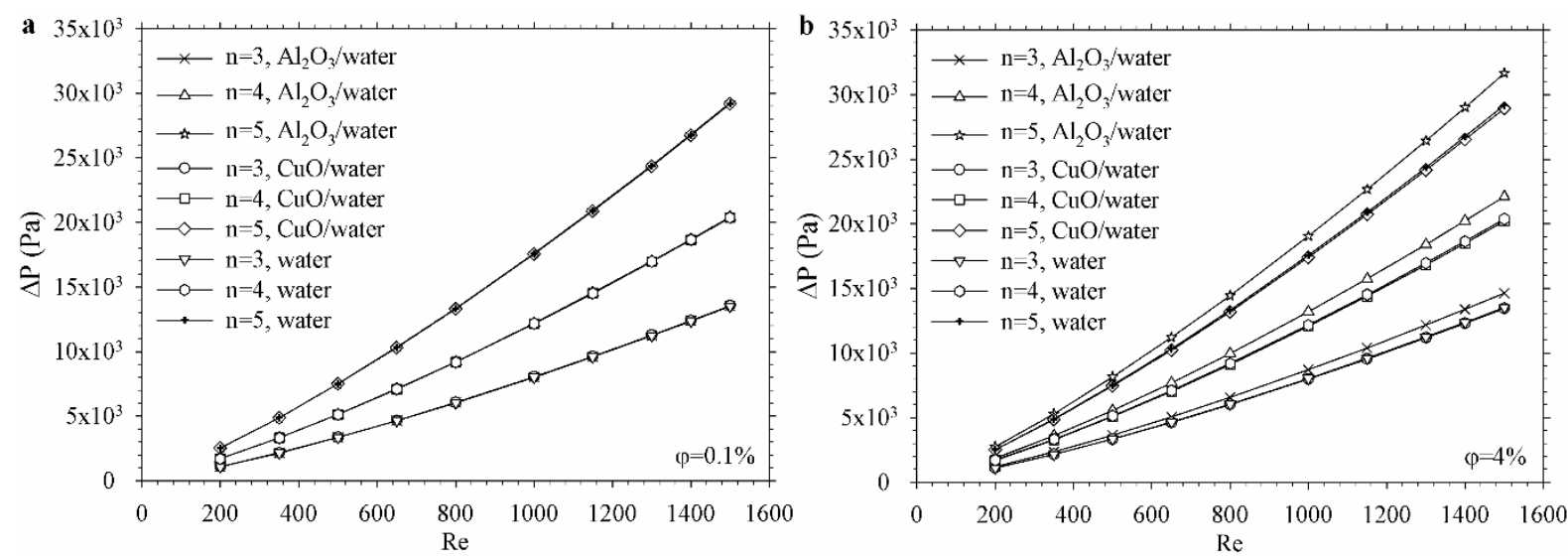

Figure 12. The effect of nanofluid type and $n$ on $\triangle P$ at different $\varphi$ values for the $\mathrm{CuO}$-water and $\mathrm{Al}_{2} \mathrm{O}_{3^{-}}$ water nanofluids $\boldsymbol{a} \varphi=0.1 \% \boldsymbol{b} \varphi=4 \%$

$\mathrm{f}$ at various $\varphi$ values for $\mathrm{Al}_{2} \mathrm{O}_{3}$-water nanofluid is given in Figure 13 as a function of $\mathrm{Re}$ for $\mathrm{n}=3$ and 5 . As seen in Figure 13, while Re enhances, $\mathrm{f}$ decreases. This can be interpreted as that increasing Reynolds number results in decreasing temperature leading to higher viscosities. High viscosity generates high 
pressure drop leading to higher friction factor. Results show that $\varphi$ does not induce a noticeable change in the average Fanning friction factor.
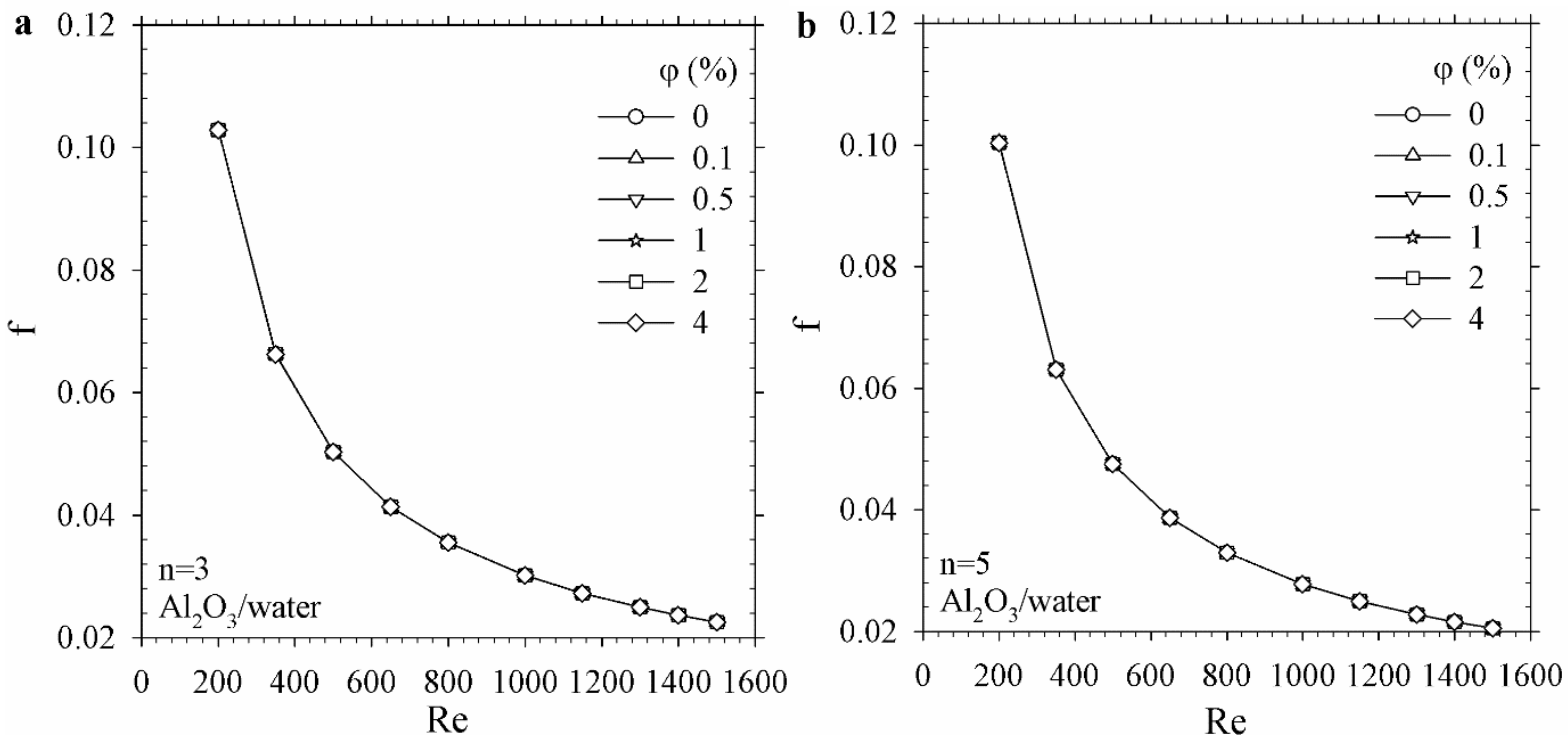

Figure 13. Average $f$ versus Re at different $\varphi$ values for $\mathrm{Al}_{2} \mathrm{O}_{3}$-water nanofluid; $\boldsymbol{a} n=3, \boldsymbol{b} n=5$

In Figure 14, average $\mathrm{f}$ is plotted against $\mathrm{Re}$ for both $\mathrm{CuO}$-water nanofluid and $\mathrm{Al}_{2} \mathrm{O}_{3}$-water nanofluid at the MC numbers of three, four and five in MCHS for $\varphi=4 \%$. At a given Re, $f$ decreases with enhancing MC number. Also, $f$ diminishes with increasing Re for both nanofluids. It has also been observed that the type of nanofluid is not effective on the $\mathrm{f}$.

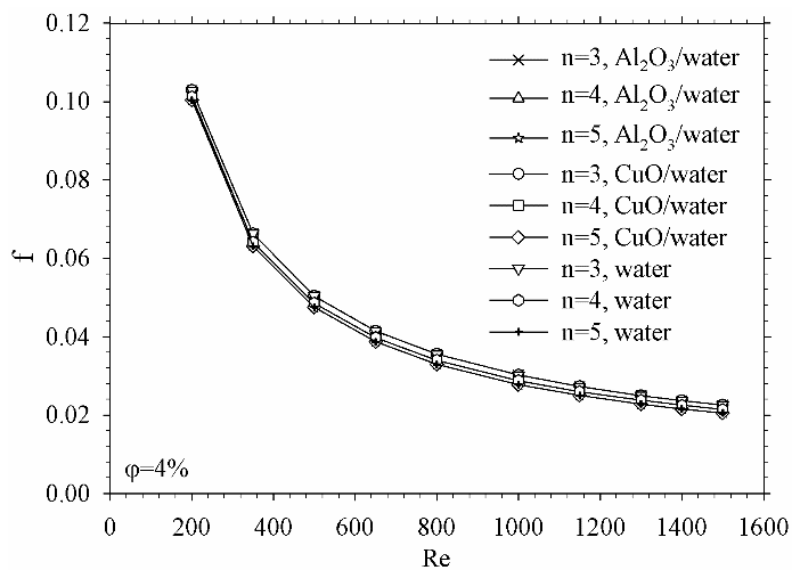

Figure 14. The effect of nanofluid type and $n$ on $f$ at $\varphi=4 \%$

\subsubsection{Thermal performance evaluation of nanofluids according to performance index}

When nanoparticle is added into base fluid, it is viewed that both heat transfer and pressure drop enhance. In order to see whether the adding of nanoparticle into base fluid is suitable or not, performance index $(\eta)$ is calculated as [30-32]:

$$
\eta=\left(h_{n f} / h_{b f}\right) /\left(\Delta P_{n f} / \Delta P_{b f}\right) .
$$

Thermal performances of nanofluids are evaluated according to performance index. Therefore, performance index is presented as a function of Re in Figure 15 for the lowest and highest values of $\varphi$ of $\mathrm{Al}_{2} \mathrm{O}_{3}$-water nanofluid and $\mathrm{CuO}$-water nanofluid at different $\mathrm{MC}$ numbers. Results show that performance index reduces 
with enhancing Re. Results indicate that the performance index for $\mathrm{CuO}$-water nanofluid is greater than unity for all conditions. However, $\eta$ for $\mathrm{Al}_{2} \mathrm{O}_{3}$-water nanofluid is less than unity. In other words, according to the performance index, using of $\mathrm{Al}_{2} \mathrm{O}_{3}$-water nanofluid is not suitable while $\mathrm{CuO}$-water nanofluid is appropriate. Performance index decreases with increasing $\mathrm{MC}$ number in heat sink for $\mathrm{Al}_{2} \mathrm{O}_{3}$-water nanofluid at high $\mathrm{Re}$ and for $\mathrm{CuO}$-water nanofluid at $\varphi=4 \%$. That is, MCHS with $\mathrm{n}=5$ has less performance than MCHS with $n=3$. Figure 15 also shows that performance index of nanofluid with $\varphi=4 \%$ is greater than that of nanofluid with $\varphi=1 \%$. It is also seen that using $\mathrm{CuO}$-water nanofluid at low volume concentration, i.e. at $\varphi=0.1 \%$, has no noticeable effect on $\eta$.

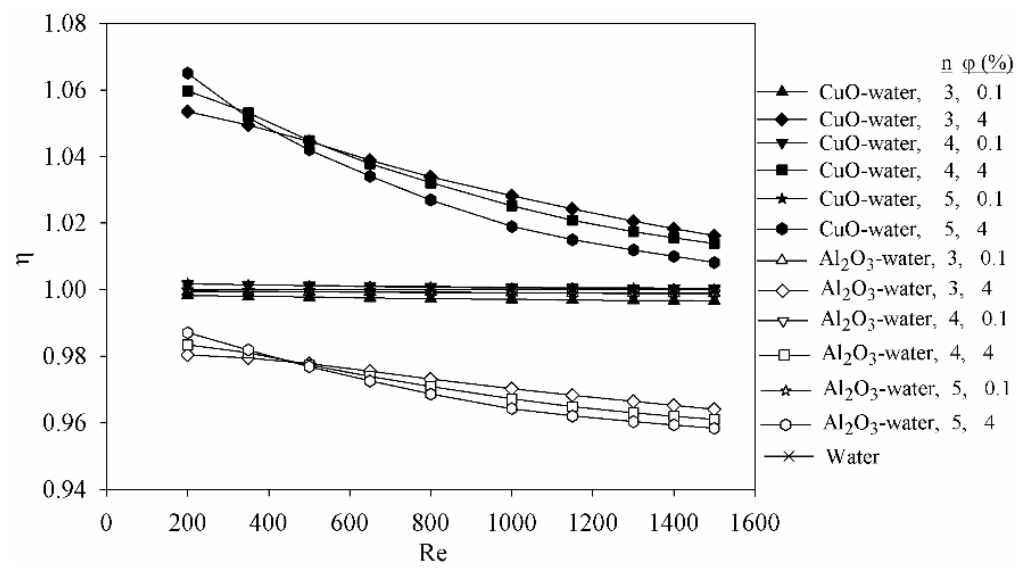

Figure 15. $\eta$ versus Re

\section{CONCLUSION}

Laminar flow and heat transfer characteristics inside a trapezoidal MCHS was examined numerically for nanofluid at same heat transfer surface area. Investigated parameters are $\operatorname{Re}(200 \leq \operatorname{Re} \leq 1500)$, the type of nanofluid ( $\mathrm{CuO}$-water nanofluid and $\mathrm{Al}_{2} \mathrm{O}_{3}$-water nanofluid), nanoparticle volume concentration $(\varphi=0$ $4 \%$ ), and MC number ( $n=3-5$ ) in the MCHS. For the problem of application of constant surface heat flux to the top plate of the MCHS and using copper material as a solid, the studying of the effect of nanofluid type, microchannel number in heat sink, $\varphi$ and Re on the characteristics of heat transfer and flow are the novelties of this study. Prominent findings are summarized as below:

$\checkmark$ Fluid outlet temperature reduces with increasing mass flow rate but increases slightly when $\varphi$ value increases.

$\checkmark \mathrm{h}$ enhances with enhancing Re and MC number in MCHS. In addition, as $\varphi$ value increases, the increase in $\mathrm{h}$ is higher in the $\mathrm{Al}_{2} \mathrm{O}_{3}$-water nanofluid compared to the $\mathrm{CuO}$-water nanofluid.

$\checkmark$ A noticeable increase in $\mathrm{Nu}$ occurs with increasing $\mathrm{Re}$, but reduces with enhancing $\varphi$ value and number of channels.

$\checkmark$ A significant decrease occurs in f value with increasing Re. $\varphi$ value does not cause a noticeable change in $\mathrm{f}$ value. It is seen that nanofluid type is not effective on $\mathrm{f}$ value.

$\checkmark \Delta \mathrm{P}$ raises with raising in $\mathrm{Re}$ and $\mathrm{MC}$ number. When $\varphi$ increases, $\Delta \mathrm{P}$ of the $\mathrm{Al}_{2} \mathrm{O}_{3}$-water nanofluid is greater than the $\Delta \mathrm{P}$ of the $\mathrm{CuO}$-water nanofluid. $\Delta \mathrm{P}$ for nanofluids is higher than that of pure water (i.e. $\varphi=0 \%$ ) owing to higher viscosity.

$\checkmark$ Thermal performance increases with decreasing $\mathrm{MC}$ number. Thermal performance for the CuO-water nanofluid is higher than that of $\mathrm{Al}_{2} \mathrm{O}_{3}$-water nanofluid.

\section{CONFLICTS OF INTEREST}

No conflict of interest was declared by the authors. 


\section{NOMENCLATURE}

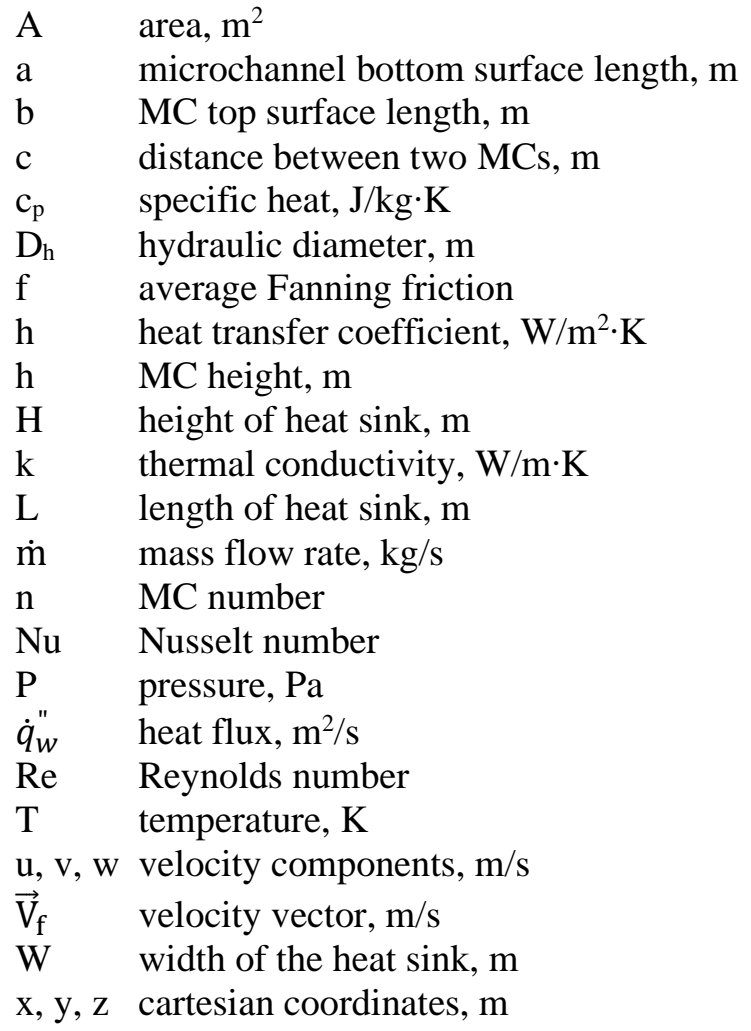

\section{Greek Letters}

$\alpha \quad$ thermal diffusivity, $\mathrm{m}^{2} / \mathrm{s}$

$\rho \quad$ density, $\mathrm{kg} / \mathrm{m}^{3}$

$\mu \quad$ dynamic viscosity, $\mathrm{kg} / \mathrm{m} \cdot \mathrm{s}$

$\eta \quad$ performance index

$\varphi \quad$ nanoparticle concentration

\section{Subscripts}

$\begin{array}{ll}\text { atm } & \text { atmosphere } \\ \text { bf } & \text { base fluid } \\ \text { f } & \text { fluid } \\ \text { i } & \text { inlet } \\ \text { nf } & \text { nanofluid } \\ \text { o } & \text { outlet } \\ \text { p } & \text { particle } \\ \text { r } & \text { ratio } \\ \text { s } & \text { solid/surface } \\ \text { w } & \text { wall }\end{array}$

\section{Abbreviations}

MC microchannel

MCHS microchannel heat sinks 


\section{REFERENCES}

[1] Kaya, H., Ekiciler, R., Arslan, K., "CFD analysis of laminar forced convective heat transfer for $\mathrm{TiO}_{2}$ /water nanofluid in a semi-circular cross-sectioned micro-channel", Journal of Thermal Engineering, 5: 123-137, (2019).

[2] Kaya, H., Ekiciler, R., Arslan, K., "Entropy generation analysis of forced convection flow in a semi-circular shaped microchannel with $\mathrm{TiO}_{2}$ /water nanofluid", Heat Transfer Research, 50: 335$348,(2019)$.

[3] Kumar, P., "Numerical investigation of fluid flow and heat transfer in trapezoidal microchannel with groove structure", International Journal of Thermal Sciences, 136: 33-43, (2019).

[4] Vinoth, R., Kumar, D. S., "Channel cross section effect on heat transfer performance of oblique finned microchannel heat sink", International Communications in Heat and Mass Transfer, 87: 270-276, (2017).

[5] Vinoth, R., Kumar, D. S., "Experimental investigation on heat transfer characteristics of an oblique finned microchannel heat sink with different channel cross sections", Heat and Mass Transfer, 54: 3809-3817, (2018).

[6] Ohadi, M., Choo, K., Dessiatoun, S., Cetegen, E., "Emerging applications of microchannels. In: Next generation microchannel heat exchangers", SpringerBriefs in Applied Sciences and Technology, Springer, New York, (2013).

[7] Sheikhalipour, T., Abbassi, A., "Numerical analysis of nanofluid flow inside a trapezoidal microchannel different approaches", Advanced Powder Technology. DOI: https://doi.org/10.1016/j.apt.2018.04.010, (2018).

[8] Sharma, D., Singh, P. P., Garg, H., "Comparative study of rectangular and trapezoidal microchannels using water and liquid metal”, Procedia Engineer, 51: 791-796, (2013).

[9] Wu, H. Y., Cheng, P., "An experimental study of convective heat transfer in silicon microchannels with different surface conditions", International Journal of Heat and Mass Transfer, 46: 25472556, (2003).

[10] Wu, H. Y., Cheng, P., "Friction factors in smooth trapezoidal silicon microchannels with different aspect ratios", International Journal of Heat and Mass Transfer, 46: 2519-2525, (2003).

[11] Chein, R., Chuang, J., "Experimental microchannel heat sink performance studies using nanofluids", International Journal of Thermal Sciences, 46: 57-66, (2007).

[12] Fani, B., Kalteh, M., Abbassi, A., "Investigating the effect of Brownian motion and viscous dissipation on the nanofluid heat transfer in a trapezoidal microchannel heat sink", Advanced Powder Technology, 26: 83-90, (2015).

[13] Li, J., Kleinstreuer, C., "Thermal performance of nanofluid flow in microchannels", International Journal of Heat and Fluid Flow, 29: 1221-1232, (2008).

[14] Wu, X., Wu, H., Cheng, P., "Pressure drop and heat transfer of $\mathrm{Al}_{2} \mathrm{O}_{3}-\mathrm{H}_{2} \mathrm{O}$ nanofluids through silicon microchannels", Journal of Micromechanics and Microengineering, 19: 105020, (2009).

[15] Li, J., Kleinstreuer, C., "Entropy generation analysis for nanofluid flow in microchannels", Journal of Heat Transfer, 132: 122401, (2010). 
[16] Mohammed, H. A., Gunnasegaran, P., Shuaib, N. H., "Influence of various base nanofluids and substrate materials on heat transfer in trapezoidal microchannel heat sinks", International Communications in Heat and Mass Transfer, 38: 194-201, (2011).

[17] Singh, P. K., Harikrishna, P. V., Sundararajan, T., Das, S. K., "Experimental and numerical investigation into the heat transfer study of nanofluids in microchannel", Journal of Heat Transfer -T ASME, 133: 121701, (2012).

[18] Fani, B., Abbassi, A., Kalteh, M., "Effect of nanoparticles size on thermal performance of nanofluid in a trapezoidal microchannel-heat-sink", International Communications in Heat and Mass Transfer, 45: 155-161, (2013).

[19] Yang, Y. T., Tsai, K. T., Wang, Y. H., Lin, S. H., "Numerical study of microchannel heat sink performance using nanofluids", International Communications in Heat and Mass Transfer, 57: 27$35,(2014)$.

[20] Yang, Y. T., Wang, Y. H., Huang, B. Y., "Numerical optimization for nanofluid flow in microchannels using entropy generation minimization”, Numerical Heat Transfer Applications, 67: 571-588, (2015).

[21] Sheikhalipour, T., Abbassi, A., "Numerical investigation of nanofluid heat transfer inside trapezoidal microchannels using a novel dispersion model", Advanced Powder Technology, 27: 1464-1472, (2016).

[22] Vinoth, R., Kumar, D. S., "Numerical study of inlet cross-section effect on oblique finned microchannel heat sink", Thermal Science, 22: 2747-2757, (2018b).

[23] Bakhshi, H., Khodabandeh, E., Akbari, O., Toghraie, D., Joshaghani, M., "Investigation of laminar fluid flow and heat transfer of nanofluid in trapezoidal microchannel with different aspect ratios", International Journal of Numerical Methods for Heat \& Fluid Flow, 29: 1680-1698, (2018).

[24] Khodabandeh, E., Abbassi, A., "Performance optimization of water- $\mathrm{Al}_{2} \mathrm{O}_{3}$ nanofluid flow and heat transfer in trapezoidal cooling microchannel using constructal theory and two phase EulerianLagrangian approach”, Powder Technology, 323: 103-114, (2018).

[25] Tran, N., Chang, Y. J., Wang, C. C., "Optimization of thermal performance of multi-nozzle trapezoidal microchannel heat sinks by using nanofluids of $\mathrm{A}_{2} \mathrm{O}_{3}$ and $\mathrm{TiO}_{2}$ ", International Journal of Heat and Mass Transfer, 117: 787-798, (2018).

[26] Jaferian, V., Toghraie, D., Pourfattah, F., Akbari, O. A., Talebizadehsardari, P., "Numerical investigation of the effect of water $/ \mathrm{Al}_{2} \mathrm{O}_{3}$ nanofluid on heat transfer in trapezoidal, sinusoidal and stepped microchannels", International Journal of Numerical Methods for Heat \& Fluid Flow, 30: 2439-2465, (2020).

[27] Incropera, F. P., DeWitt, D. P., Bergman, T. L., Lavine, A. S., "Principles of heat and mass transfer", John Wiley and Sons Inc., Singapore, (2013).

[28] Koyuncuoglu, A., Jafari, R., Okutucu-Ozyurt, T., Kulah, H., "Heat transfer and pressure drop experiments on CMOS compatible microchannel heat sinks for monolithic chip cooling applications", International Journal of Thermal Sciences, 56: 77-85, (2012).

[29] Kandlikar, S. G., Garimella, S., Li, D., Colin, S., King, M. R., "Heat transfer and fluid flow in minichannels and microchannels", Elsevier, USA, (2006). 
[30] Pakdaman, M. F., Akhavan-Behabadi, M. A., Razi, P., "An experimental investigation on thermophysical properties and overall performance of MWCNT/heat transfer oil nanofluid flow inside vertical helically coiled tubes”, Experimental Thermal and Fluid Science, 40: 103-111, (2012).

[31] Ahmed, H. E., Yusoff, M. Z., Hawlader M. N. A., Ahmed M. I., Salman B. H., Kerbeetf A. Sh., "Turbulent heat transfer and nanofluid flow in a triangular duct with vortex generators", International Journal of Heat and Mass Transfer, 105: 495-504, (2017).

[32] Boukerma, K., Kadja, M., "Convective heat transfer of $\mathrm{Al}_{2} \mathrm{O}_{3}$ and $\mathrm{CuO}$ nanofluids using various mixtures of water-ethylene glycol as base fluids", Engineering, Technology \& Applied Science Research, 7: 1496-1503, (2017). 